\title{
Surgical Management of Nystagmus
}

\author{
J. P. LEE
}

London

\begin{abstract}
Summary
The indications and techniques for the management of nystagmus are described and discussed. Surgical treatment is of value in patients with consistent head posture. Guidelines for surgery are given.
\end{abstract}

The ophthalmologist will normally be asked to consider the treatment of nystagmus in two main categories-congenital and acquired. Patients with congenital nystagmus may have pendular nystagmus, but this is much more frequently associated with severe visual disability due to ocular or intracranial pathology. More typically, they show a jerk nystagmus with the fast phase to the side of the fixing eye, often with characteristic abnormalities on testing with optokinetic stimuli. Because of the resemblance to latent nystagmus, Dell'Osso has coined the term 'Manifest Latent Nystagmus'. ${ }^{1}$

Many of these patients have no discernible abnormality on routine ophthalmological examination. Patients with oculo-cutaneous and ocular albinism always have nystagmus, so a careful search for iris transillumination is essential. The foveal reflex is often said to be abnormal in these patients, but this can be difficult to assess. A family history is more easily elicited in ocular albinism and the mother will show the characteristic fundal appearances of the carrier state. Only a relatively small proportion of albinos are whitehaired and pink-eyed, so the diagnosis needs to be suspected. All albino mammals appear to have a characteristic abnormality of the anatomy of the optic chiasm with appropriate alteration of the hemifield visual evoked response. Fitzgerald and Billson ${ }^{2}$ have described similar responses in patients with congenital esotropia, latent nystagmus and dissociated vertical divergence, but confirmation of this work is not yet available. Many patients with congenital nystagmus are rather hypopigmented. This has been termed 'albinoidism' and is said to be inherited as an autosomal dominant characteristic. Simon et al. ${ }^{3}$ described a group of this type, none of whom were classic albinos.

Some families appear to have dominantly inherited congenital nystagmus without other detectable abnormality. Finally, loss of one eye may precipitate typical congenital nystagmus in the other eye, presumably by 'manifesting' latent nystagmus which existed prior to the visual loss. ${ }^{4}$

Most patients with congenital nystagmus have discovered adaptive strategies to improve their visual performance. Most find that holding the object of regard very close to the eyes and inducing convergence produces 'damping' of the nystagmus with improved acuity. Other patients discover that adoption of an abnormal head posture, with the eyes directed into an eccentric gaze position, also damps the nystagmus and improves acuity. The commonest posture is a face turn to one side. Less common are chin elevation or depression or tilt of the head. Finally, many 
patients can improve concentration by means of a slight head shake or nod, of which they are often unaware.

Patients present with a variety of complaints. Most have poor visual acuity at distance. This must be measured with and without a head posture if present. Some patients notice oscillopsia, others just report blurring of vision. The appearance of an abnormal head posture is a cosmetic problem and some patients train themselves to hold their heads straight despite poor vision in the interests of improved appearance. One of the commonest reasons patients with congenital nystagmus are seen is because they wish to pass the sight requirements for the driving test. Sadly, this is often not possible.

Patients with acquired nystagmus and oscillopsia may be referred to the ophthalmologist for treatment. Among many possible diagnoses here are spasmus nutans, downbeat nystagmus, oculo-palatal myoclonus, and brainstem demyelination. Other more exotic variants include periodic alternating nystagmus, congenital nystagmus with periodic alternating head turn ${ }^{5}$ and monocular nystagmus such as that caused by superior oblique myokymia.

\section{Non-Surgical Management}

This is mentioned for completeness. All cases require a good cycloplegic refraction, as many patients are astigmatic and anisometropic. Glasses occasionally improve ocular stability dramatically and even small errors should be corrected. Some authorities advise contact lenses on similar grounds, and minus lenses have been used to stimulate accommodation. and secondarily, convergence to improve ocular stability. Prism therapy may be used in two ways: base-out prisms may be used to stimulate convergence to stabilise the eyes, and prisms may be prescribed with the base towards the head turn to allow eccentric ocular position but a straight head. Because of the very large power of the prisms, they are either very heavy and obvious, if of glasses or plastic, or degrade acuity, if used as Fresnel membrane prisms. Accordingly, they are probably best used diagnostically to decide if surgery will help or to deal with small residual head turns after surgery. Some drugs are of value: Clonazepam certainly helps in periodic alternating nystagmus and may help some cases of congenital nystagmus. Finally, various 'fringe' therapies have been advocated: pleoptics,${ }^{10}$ biofeedback ${ }^{7}$ and flashing red lights $^{8}$. The last-named treatment has the great advantage of simultaneously treating amblyopia, or so it is claimed!

\section{Surgical Treatment}

The patient who presents with nystagmusblockage syndrome (congenital esotropia, head turn to the side of the fixing eye, nystagmus on abduction, and usually amblyopia), is best managed by aggressive medial rectus surgery on both eyes to take advantage of the presumed stabilising effect of medial rectus innervation without the associated esotropia. The standard procedure is bilateral medial rectus recessions (to $10.5 \mathrm{~mm}$ from the limbus) with bilateral posterior fixation (Faden) procedures.

Much more commonly, however, an abnormal head posture is the indication for surgical treatment. Most authorities feel that turns, of less than $15^{\circ}$ are best left alone. The size of the head posture may be judged clinically, by photography, or by use of a torticollometer." An alternative is to use an array of fixation targets such as LEDs and assess the eccentricity of gaze where nystagmus is least. ${ }^{10}$

The principle of surgery for a face turn is to rotate the eyes towards the head turn, or alternatively, to induce a relative gaze palsy towards the side that the eyes are normally directed. This was first suggested independently by Anderson" who advocated recessing the 'agonist' of the head turn on each eye, Goto, ${ }^{12}$ who resected the 'antagonist' muscle of each eye, and Kestenbaum ${ }^{13}$ who performed a combination of both approaches. Parks ${ }^{14}$ advocated his modification of the Kestenbaum procedure, the ' $5,6,7,8$ ' procedure, with recessions of one medial rectus $5 \mathrm{~mm}$ and one lateral rectus $7 \mathrm{~mm}$, with resections of the other medial rectus $6 \mathrm{~mm}$ and other lateral rectus $8 \mathrm{~mm}$. This was felt to be the practical maximum muscle surgery at the time. However, Calhoun ${ }^{15}$ and Nelson et al. ${ }^{16}$ along with others have advocated 'augmented' Kestenbaum surgery. Nelson suggests a 40 per cent augmentation $(7,8.4,9.8,11.2 \mathrm{~mm})$ for head 
turns up to $30^{\circ}$, and 60 per cent $(8,9.6,11.2$, $12.8 \mathrm{~mm}$ ) for head turns of $45^{\circ}$ or more. The object of this approach is to reduce the need for repeat surgery. I prefer to use the Parks method, warning the parents that initially results will be good, but will probably deteriorate with time. Should that happen, I re-resect the previously resected muscles by $5 \mathrm{~mm}$ each and perform Faden (posterior fixation) procedures on the recessed muscles.

If a squint is present, it is possible to add algebraically the amounts of surgery required, remembering to do the most surgery on the fixing eye as that determines the head turn.

\section{Example}

Face turn left $30^{\circ}$

Right esotropia 25 prism dioptres

$\begin{array}{lcccc} & R L R & R M R & L M R & L L R \\ \text { For nystagmus } & -7 \mathrm{~mm} & +6 \mathrm{~mm} & -5 \mathrm{~mm} & +8 \mathrm{~mm} \\ \text { For esotropia } & +7 \mathrm{~mm} & -5 \mathrm{~mm} & & \end{array}$

Perform: $\quad 0 \mathrm{~mm}+1 \mathrm{~mm}-5 \mathrm{~mm}+8 \mathrm{~mm}$

In this case, surgery in the left eye only would probably fulfil both objectives of correction of head turn and esotropia.

It is crucial to be sure that the head position and null zone are consistent on repeated visits as there may be two null zones or even a periodic alternating null zone.

\section{Case Report}

N.B., a white male born in 1971 was seen at the age of 10 years with congenital nystagmus and a cosmetically poor face turn to the right. At that time he was noted to have null points in right and left gaze, although he preferred the null in left gaze. In March 1982, he had symmetrical muscle surgery, with right medial rectus recession, right lateral rectus resection, left lateral rectus recession and a left medial rectus resection, all by $7 \mathrm{~mm}$. He was said to look better postoperatively. By February 1984, he had a cosmetically poor head turn left, with symptoms. In January 1985 , he had right medial rectus advancement $6 \mathrm{~mm}$, right lateral rectus recession $8 \mathrm{~mm}$, left medial rectus recession $5 \mathrm{~mm}$ and left lateral rectus resection $9 \mathrm{~mm}$. He again seemed improved after surgery, apart from some residual left inferior oblique overaction, which responded to a recession in March 1986. However, by January 1987 he could clearly be seen to have a cyclic alternating null point with a cycle about 2 minutes long. A trial of Clonazepam is planned.

Vertical head postures (chin-up or down) may be managed in an analogous fashion. These are much rarer, and, interestingly, the waveform of the nystagmus is nearly always horizontal. Again, the eyes are rotated to follow the head, so, for instance, for a chin-down posture one would resect both inferior recti equally 4-6 $\mathrm{mm}$ and recess both superior recti equally a similar amount. It is very important to maintain very accurate measurements as it is quite easy to induce a secondary vertical deviation and cause diplopia or a new abnormal head posture. Minor degrees of head tilt are very common in combination with head turn and are probably best ignored. Marked head tilts may be managed by superior oblique weakening on the same side and inferior oblique weakening on the other. ${ }^{17}$

\section{Botulinum Toxin Therapy}

The effect of Botulinum toxin is transient, and therefore it has some applications in terms of diagnosis as to whether surgery will be of value. However, its longterm effects might be predicted to be of little or no value.

Our experience with Botulinum toxin for nystagmus is reported elsewhere. ${ }^{18}$ D'Esposito et al. ${ }^{19}$ reported some results but did not give any follow-up data.

\section{Conclusion}

In conclusion, if a patient has a significant compensatory head posture, extraocular muscle surgery of the Kestenbaum or modified Kestenbaum type is of value in improving cosmesis and ocular stability. Although the initial effect tends to wear off slightly, reoperation is possible. Alternative null points should be looked for, and are a contraindication to surgery. Chin elevation and depression and head tilt may be managed by similar surgical techniques.

I would like to thank Mrs. S. McKeever for preparing the manuscript.

\section{References}

${ }^{1}$ Dell-Osso LF, Schmidt D, Daroff R: Latent, manifest latent and congenital nystagmus. Arch Ophthalmol 1979, 97: 1877-85.

${ }^{2}$ Fitzgerald BA and Billson FA: Dissociated vertical deviation: evidence of abnormal visual pathway projection. Br J Ophthalmol 1984, 68: 801-6.

${ }^{3}$ Simon JW, Kandel GL, Krohel GB, Nelson PJ: 
Albinotic characteristics in congenital nystagmus. Am J Ophthalmol 1984, 97: 320-7.

${ }^{4}$ Harcourt B and Spencer F: Manifest latent nystagmus affecting patients with uniocular congenital blindness. In Transactions of the 14 th Meeting of the European Strabismological Association, ed Gregerson E, APS Copenhagen, 1985, pp 25964.

${ }^{5}$ Robb RM: Periodic alteration of null point in congenital nystagmus. Arch Ophthalmol 1972, 87: 169-73.

${ }^{6}$ Cuppers C and Sevrin G: Le Probleme de la fixation dans L'amblyopie et particularierment dans le nystagmus. Bull Soc Fr Ophthalmol 1956, 69: 359.

${ }^{7}$ Abadi RV, Carden D, Simpson J: A new treatment for congenital nystagmus. Br J Ophthalmol 1980 , 64: $2-6$.

${ }^{8}$ Mallett R: The treatment of congenital idiopathic nystagmus by intermittent photic stimulation. Ophthal Physiol Opt 1983, 3: 341-56.

${ }^{9}$ Sradj N: Torticollometry for direct measurement of head posture. Am Orthopt J 1984, 34: 117-18.

${ }^{10}$ Dell'Osso LF and Flynn JT: Congenital nystagmus surgery: a quantitative evaluation of the effects. Arch Ophthalmol 1979, 97: 462-9.

${ }^{11}$ Anderson JR: Causes and treatment of congenital eccentric nystagmus. Br J Ophthalmol 1953, 37: 267-80.
12 Goto N: A study of optic nystagmus by the electrooculogram. Acta Soc Ophthalmol Jap 1954, 58: 851-65.

${ }^{13}$ Kestenbaum A: Nouvelle operation de nystagmus. Bull Soc Ophthalmol Fr 1954, 2: 1071-8.

${ }^{14}$ Parks MM: Congenital nystagmus surgery. Am Orthopt J 1973, 23: 35-39.

${ }^{15}$ Calhoun JH and Harley RD: Surgery for abnormal head position in congenital nystagmus. Trans Am Ophthalmol Soc 1973, 71: 70-87.

${ }^{16}$ Nelson LB, Ervin-Mulley LD, Calhoun JH, Harley RD, Keisler MS: Surgical management for abnormal head position in nystagmus: the augmented modified Kestenbaum procedure. $\mathrm{Br} J$ Ophthalmol 1984, 68: 796-800.

${ }^{17}$ Conrad HG and de Decker W: Torsional Kestenbaum procedure, evolution of a surgical concept. In Strabismus II ed Reinecke RD, 1984, Grune and Stratton, New York, pp 301-14.

${ }^{18}$ Lee J, Elston J, Vickers, S, Powell C, Ketley, J, Hogg C: Botulinum Toxin Therapy for Squint. Eye 1988 (in press).

${ }^{19}$ D'Esposito M, Daniele A, Calace P, Cortest G: Our experience on nystagmus treatment with botulinum toxin, (Preliminary report). In proceedings of VIth Congress of the International Strabismological Association ed Campos E 1986. 